\title{
Gender Difference in Breast Tissue Size in Infancy: Correlation with Serum Estradiol
}

\author{
IDA MARIA SCHMIDT, MARLA CHELLAKOOTY, ANNE-MAARIT HAAVISTO, \\ KIRSTEN ARNTZ BOISEN, IDA NORGIL DAMGAARD, ULLA STEENDAHL, JORMA TOPPARI, \\ NIELS ERIK SKAKKEBÆK, AND KATHARINA MARIA MAIN \\ University Department of Growth and Reproduction, Rigshospitalet, Copenhagen, Denmark [I.M.S., M.C., \\ A-M.H., K.A.B., I.N.D., U.S., N.E.S., K.M.M.]; Departments of Paediatrics and Physiology, University of
}

Turku, Turku, Finland [J.T.]

\begin{abstract}
ABST
Breast tissue in newborn infants is considered to be physio-
logic and mainly related to exposure to maternal hormones in
utero or through breast-feeding. However, controversy exists as
to whether breast tissue in later infancy is under the influence of
endogenous hormones. Children at $2-4$ mo of age have a surge
of reproductive hormones, including estradiol, which may affect
the mammary gland. In a prospective cohort study of 1126
healthy, 3 -mo-old infants, breast tissue size and reproductive
hormones were measured. We found that palpable breast tissue
(diameter $\geq 3$ mm) is a common physiologic condition present in
$78.9 \%$ of children, significantly more frequent ( $p<0.001)$ and
larger $(p<0.001)$ in girls than in boys. Girls had significantly
higher median estradiol levels than boys (30.0 versus 21.0
pmol/L, $p<0.001)$. In a multiple regression model including
\end{abstract}
Most boys and girls have some degree of measurable breast tissue at birth, which is considered to be physiologic and related to maternal and infant hormone levels (1-3). A number of studies show that breast tissue persists for some weeks or months, during which it is most likely related to endogenous mammotrophic hormones, although a prolonged effect of maternally derived hormones cannot be ruled out $(4-6)$. It is known that a considerable secretion of reproductive hormones occurs early postnatally $(7,8)$. However, the potential association of these hormones to breast tissue size in infants has, to our knowledge, not previously been described.

The aim of the present study was to determine the incidence of palpable breast tissue in healthy 3-mo-old children, to examine possible gender differences, and to correlate breast

Received March 12, 2002; accepted June 17, 2002.

Correspondence: Ida Maria Schmidt, M.D., University Department of Growth and Reproduction, Rigshospitalet, Section 5064, Blegdamsvej 9, DK-2100 Copenhagen, Denmark; e-mail: rh03096@rh.dk

Supported by the Danish Research Council (no. 9700833), Research Foundation of The Copenhagen Hospital Corporation (no. 109/00), EU-grant Envir. Reprod. Health (no. QLK4-1999-01422), and the Ville Heise Foundation.

DOI: 10.1203/01.PDR.0000032071.90497.50 breast tissue size given as quartiles as the dependent variable and weight for gestational age, subscapular skinfold, weight at 3 mo of age and serum estradiol as independent variables, a gender difference was shown. In girls, the estradiol level was positively $(p<0.03)$ correlated to breast quartile. In boys, no correlations were found. Whether the stimulation of the mammary gland in infancy represents a developmental window that is of biologic significance for breast development and pathology in adulthood remains to be defined. (Pediatr Res 52: 682-686, 2002)

\section{Abbreviations \\ WGA, weight for gestational age \\ SHBG, sex hormone binding globulin}

tissue size with serum levels of endogenous reproductive hormones.

\section{MATERIALS AND METHODS}

A prospective cohort study was performed between 1997 and 2001 at the University Hospital of Copenhagen. The children were recruited prenatally. Women who geographically belonged to the hospital referral area (not referred because of expected complications in pregnancy) were consecutively asked in the first trimester of pregnancy to join the study. In the present analysis, solely mature healthy singletons were included. A total of 1126 infants were examined, 561 girls and 565 boys, median age 3.0 mo (range 2.5-3.5 mo). All children were born at term with a median gestational age of $282 \mathrm{~d}$ (range 259-300 d) and a median birth weight of $3.65 \mathrm{~kg}$ (range $1.95-5.68 \mathrm{~kg}$ ). Gestational age was routinely determined by ultrasonography in pregnancy wk 18-20. Birth weight was obtained from birth records. WGA was expressed as the deviation from the expected mean WGA (\%). For this calculation, a gender-differentiated fourth-degree polynomia was used (9) [modified by (10)]. At examination, breast tissue was identified by palpation as a firm subcutaneous disc and the diameter 
measured to the nearest $0.1 \mathrm{~mm}$ using a small slide gauge (Baty International, West Sussex, U.K.) (Fig. 1). Diameters below 3 $\mathrm{mm}$ were considered unmeasurable, i.e. equivalent to the nipple diameter, and registered as 1 . The mean breast diameter of right and left side was calculated. Body weight was measured on a digital scale (Solotop Oy, Baby-Scale Model, Helsinki, Finland) to the nearest $0.005 \mathrm{~kg}$ and the mean of three measurements was registered. Body fat was estimated by measuring subscapular skinfold using a skinfold caliper (Harpenden, British Indicators LTD, London, U.K.). The mean of three measurements to the nearest $0.1 \mathrm{~mm}$ was registered. All methods of measuring were standardized at workshops attended by all examiners.

Nonfasting venous blood was sampled from the cubital vein. Serum was stored at $-20^{\circ} \mathrm{C}$. Two hundred and thirty girls and 232 boys were randomly selected for hormone analyses. Estradiol was measured by RIA (Pantex, Santa Monica, CA, U.S.A) with a detection limit of $18 \mathrm{pmol} / \mathrm{L}$ and intra- and interassay coefficients of variation below $8 \%$ and $13 \%$, respectively. SHBG was measured by time-resolved fluoroimmunoassay (Delfia, Turku, Finland) with a detection limit of 0.23 $\mathrm{nmol} / \mathrm{L}$ and both intra- and interassay coefficients of variation below $5 \%$. Testosterone ( 227 boys and 34 girls) was measured by RIA (Coat-a Count, Diagnostic Products, Los Angeles, CA, U.S.A.) with a detection limit of $0.23 \mathrm{nmol} / \mathrm{L}$ and both intraand interassay coefficients of variation below $10 \%$. Bioavailable estradiol was calculated using the following equation: [estradiol pmol/L/(SHBG nmol/L $\times 1000)] \times 100$.

Descriptive results are given as median (2.5-97.5 percentiles) unless otherwise stated. Differences between groups were tested with Mann-Whitney or $\chi^{2}$ test. Correlations were tested with Spearman rank test and multiple linear regression analysis (stepwise) using SPSS 11.0 for Windows (SPSS Science, Chicago, IL, U.S.A.).

The study was performed according to the Helsinki II Declaration and approved by the local ethical committee [j.no. (KF) 01-030/97]. Informed written consent was given by the parents.

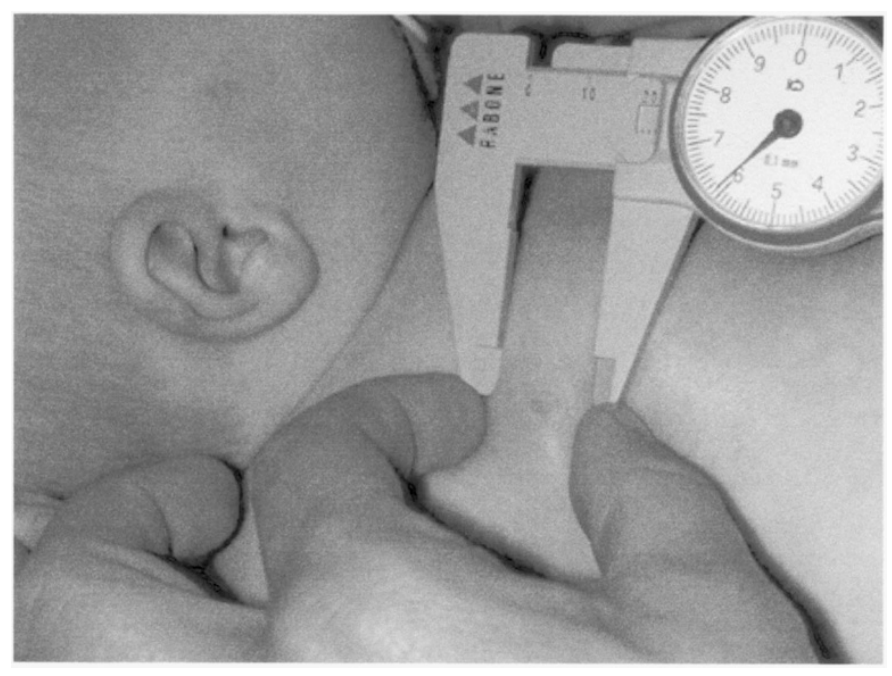

Figure 1. Identification and measurement of breast tissue size in a 3-mo-old infant.

\section{RESULTS}

At 3 mo of age, palpable breast tissue was present in $78.9 \%$ of all children, significantly more frequently in girls than in boys (girls $84.8 \%$ versus boys $72.6 \%, p<0.001$ ). In addition, we found a significant gender difference in median breast tissue size as girls had larger breasts than boys, even though the absolute level of breast tissue measurements showed some degree of interobserver variation (Table 1). To correct for this variation, we categorized the individual mean breast diameters into quartiles for each examiner separately. This grouping showed that most boys were found in the low quartiles, whereas girls showed the opposite pattern, with most measurements in the upper quartiles (Fig. 2).

Boys had a higher median birth weight than girls [boys 3.70 $(2.72-4.65) \mathrm{kg}$ versus girls $3.58(2.80-4.50) \mathrm{kg}, p<0.001]$ and weighed more than girls at the examination at 3 mo of age [6.45 (5.02-7.91) $\mathrm{kg}$ versus $5.96(4.84-7.43) \mathrm{kg}, p<0.001]$. No significant gender difference was found in WGA [boys $-0.2 \%(-23.7-+24.1 \%)$ versus girls $1.1 \%(-21.2-+24.3 \%)]$. Median subscapular skinfold measurements did not differ significantly between boys and girls $(7.3 \mathrm{~mm}$ versus $7.2 \mathrm{~mm}$, range $4.0-15.6$ versus $4.0-13.4$ ).

Girls had a significantly higher median serum estradiol level than boys ( 30.0 versus $21.0 \mathrm{pmol} / \mathrm{L}, p<0.001$, range $<18-$ 100 versus $<18-58)$ and calculated bioavailable estradiol (median 0.023 versus $0.014, p<0.001$ ). There was no correlation between subscapular skinfold and estradiol level in either boys nor girls.

Median testosterone level was significantly higher in boys than in girls $(3.28$ versus $<0.23 \mathrm{nmol} / \mathrm{L}, p<0.001)$. Serum testosterone in boys ranged from $<0.23-12.10 \mathrm{nmol} / \mathrm{L}$. whereas in girls 32 out of 34 samples were below the detection limit and the two measurable samples were very low $(0.25$ and $0.58 \mathrm{nmol} / \mathrm{L}$ ). For this reason, only a limited number of samples from girls were analyzed. There was no gender difference in median SHBG levels (boys 131 versus girls 131 $\mathrm{nmol} / \mathrm{L}$, range 26-440 versus 48-272). No correlation between estradiol and testosterone was found in either boys or girls.

In none of the groups was there any correlation between serum testosterone and breast tissue size. No estradiol to testosterone ratio was calculated for the girls, as the majority of samples were below the detection limit for testosterone. In boys, the median ratio between estradiol and testosterone was 0.005 (range $0.000-0.10$ ) and showed no correlation to breast tissue size.

In a multiple regression model including breast tissue size given as quartiles as the dependent variable and WGA, subscapular skinfold, weight at 3 mo of age, and serum estradiol as independent variables, a gender difference was shown. In girls, the estradiol level was positively $(p<0.03)$ correlated to breast quartile (Fig. 3). In boys, no correlation between breast quartile and any of the independent variables was found (Fig. 3 ). In both groups, no correlation was found between breast quartile and bioavailable estradiol when this variable was used instead of estradiol and SHBG in the same model. Grouping breast tissue size into two main categories (quartile 1-3 versus 
Table 1. Mean breast tissue (BT) diameter in healthy 3-mo-old infants measured by seven examiners

\begin{tabular}{|c|c|c|c|c|c|c|c|c|c|}
\hline & \multirow[b]{2}{*}{ Gender } & \multirow[b]{2}{*}{ All } & \multicolumn{7}{|c|}{ Examiner } \\
\hline & & & A & $\mathrm{B}$ & $\mathrm{C}$ & $\mathrm{D}$ & $\mathrm{E}$ & $\mathrm{F}$ & G \\
\hline Number of children & Girls & 561 & 132 & 181 & 71 & 58 & 24 & 55 & 40 \\
\hline \multirow[t]{2}{*}{ Median BT diameter $(\mathrm{mm})$} & Girls & 5.7 & 5.4 & 6.0 & 4.8 & 9.0 & 5.8 & 6.0 & 5.6 \\
\hline & Boys & 4.9 & 4.6 & 5.4 & 3.8 & 7.6 & 5.6 & 4.7 & 4.2 \\
\hline $95 \%$ confidence interval & Girls & $1.0-11.4$ & $1.0-9.1$ & $1.0-11.2$ & $1.0-11.7$ & $1.0-14.8$ & $1.0-8.5$ & $1.0-12.5$ & $1.0-11.0$ \\
\hline
\end{tabular}

* Mann-Whitney test.

4) strengthened the correlation with estradiol in girls $(p<$ $0.001)$, but still no correlation in boys was seen.

\section{DISCUSSION}

We found that palpable breast tissue is a common physiologic condition in 3-mo-old healthy children, significantly more frequent and pronounced in girls than in boys. This finding was not associated with differences in body weight or amount of subcutaneous fat tissue. Most previous studies have shown no gender difference in the occurrence or size of breast tissue in newborn infants $(2-4,11)$. At later ages, from 1-2 mo up to $1 \mathrm{y}$, some have reported palpable breast tissue to be more frequent in girls than in boys $(4,6)$ whereas other studies could not reproduce a gender difference $(2,3)$. However, methods of measuring breast tissue (ruler, tape measure, or comparison with a standard disc), stratification of measurements (continuous or categorized), study designs (longitudinal or crosssectional), and the age at which the children were examined vary considerably between the studies and may, to some degree, explain the conflicting results. As shown in the present study, it is difficult to standardize the measurement of breast tissue size in children as the procedure of identifying the precise borders of the mammary gland and measuring the disc is observer dependent. We have taken this into account by grouping the breast measurements into quartiles.

The sensitivity of our assays for estradiol and testosterone is better than that of most other commercially available kits. However, a considerable number of samples from infants were below the detection limit for either estradiol or testosterone. Despite these drawbacks, we were able to detect a gender difference in serum estradiol levels and a correlation between breast quartiles and serum estradiol in girls. Even though the high postnatal production of sex steroids has been known for decades, the physiologic significance of this is just emerging. There is increasing evidence that the early surge of gonadotropins in boys is important for genital growth and reproductive function $(12,13)$. Our findings indicate that breast tissue is sensitive to sex steroids very early in life. This is in line with the reported histology of breast tissue in children under $2 \mathrm{y}$ of age, which is similar to the puerperal gland of the adult female (14). At $2 \mathrm{y}$ of age, the adult pattern of epithelial phenotypes in human breast seems to be established (15). In an autopsy material estrogen receptor- $\alpha$ was found to be expressed in human female mammary tissue from wk 30 of gestation onward and it was markedly up-regulated shortly after birth (16).
The gender difference in breast tissue size may, at least partly, be due to differences in serum estradiol levels. The lack of correlation between breast tissue size and estradiol or estradiol to testosterone ratio in boys may be caused by the limited sensitivity of both the estradiol and testosterone assay used, resulting in a considerable number of undetectable values. Previously, the estradiol levels in girls with premature thelarche was thought not to be different from normal prepubertal controls. However, an ultrasensitive bioassay has recently shown that girls with premature thelarche had slightly, but significantly, higher estradiol levels than age-matched controls (17). It is, therefore, tempting to speculate that the associations between sex hormones and breast tissue size in infants may turn out to be stronger if more sensitive assays were available.

In male pubertal gynecomastia, subtle disturbances of ratios between $\Delta_{4}$-androstenedione and estrone or estradiol have been found (18). There are also strong indications that estrogens are involved in the pathogenesis of male gynecomastia as the condition has been successfully treated with antiestrogens (19) and, on an experimental basis, with aromatase inhibitors (20). In mammary epithelial cells from adult women, conversion of estrone to estradiol by 17-hydroxysteroid dehydrogenase has been detected (21). This mechanism may be of importance in infants, too. Due to limited amount of serum, we did not have the opportunity to measure other estrogens or androgens. With regard to palpable breast tissue in infancy, other factors like nutrition or hormonal environment in utero may also affect the postnatal breast tissue size or the susceptibility to endogenous hormones (6).

Sex hormone levels in early life may influence development of breast pathology such as breast cancer in adulthood (22). Thus, epidemiologic evidence suggests that females exposed to elevated levels of maternal serum estradiol during fetal life have an increased risk of breast cancer in adult life (22-26). In contrast, maternal preeclampsia, characterized by low estrogen levels, has a protective effect on the female fetus against breast cancer in adulthood (27). Russo and Russo (28) have hypothesized that hormonal exposure may influence the pathway of differentiation of breast epithelium, thereby altering the susceptibility to carcinogens.

In conclusion, our data support the assumption that the presence of palpable breast tissue in young infants is physiologic and, to some degree, associated with endogenous estradiol levels. Infancy may represent a developmental window when stimulation of the mammary gland can be of biologic 


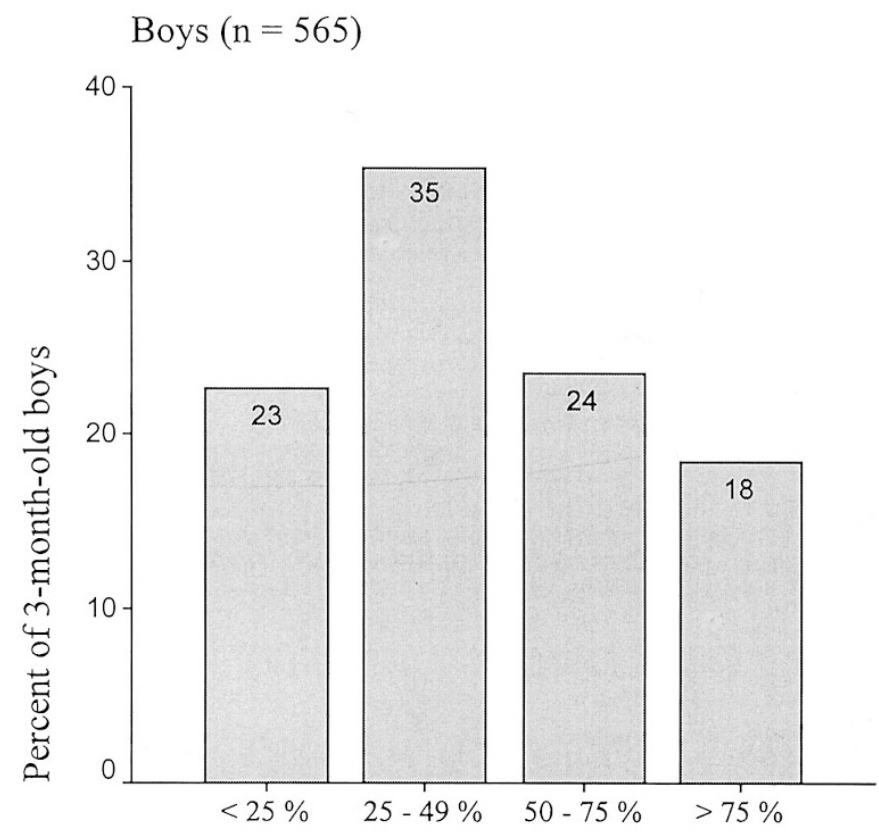

Breast tissue quartiles

Girls $(\mathrm{n}=561)$

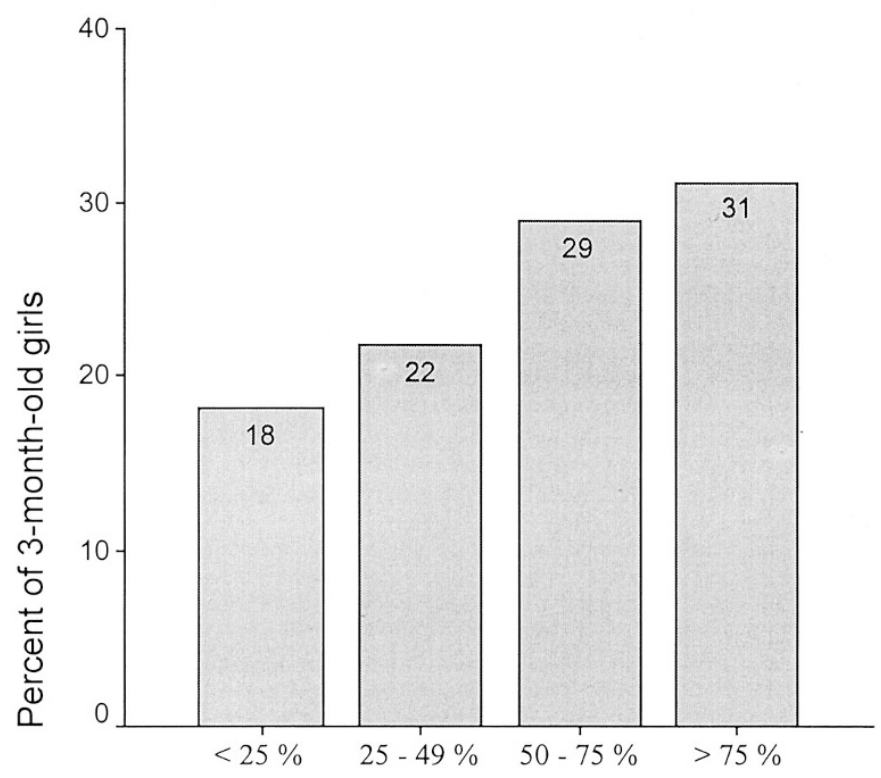

Breast tissue quartiles

Figure 2. Breast tissue size, grouped into quartiles, in 3-mo-old boys and girls.

significance for breast development and pathology in adulthood.

Acknowledgments. The authors thank the families and the Departments of Obstetrics and Gynaecology at the University Hospital of Copenhagen for their excellent cooperation.

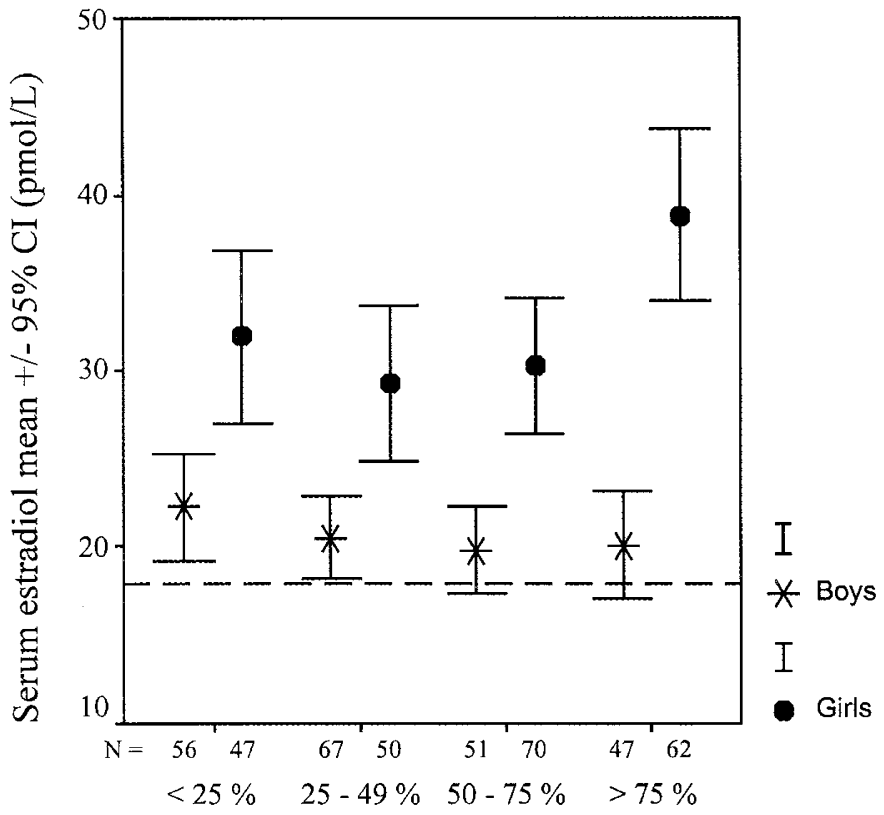

\section{Breast tissue quartiles}

Figure 3. Serum estradiol (mean $\pm 95 \%$ confidence interval) in 3-mo-old boys and girls according to breast tissue size, grouped into quartiles. Detection limit $(18 \mathrm{pmol} / \mathrm{L})$ is shown by a broken line.

\section{REFERENCES}

1. Francis GL, Hoffman WH, Gala RR, McPherson JC, Zadinsky J 1990 A relationship between neonatal breast size and cord blood testosterone level. Ann Clin Lab Sci 20:239-244

2. Madlon-Kay DJ 1986 'Witch's milk'. Galactorrhea in the newborn. Am J Dis Child 140:252-253

3. Nachtigall VC 1965 Verlaufsbeobachtungen über die physiologische Brustdrüsenschwellung der Neugeborenen. Monatsschr Kinderheilkd 113:497-498

4. McKiernan JF, Hull D 1981 Breast development in the newborn. Arch Dis Child 56:525-529

5. McKiernan JF, Hull D 1981 Prolactin, maternal oestrogens, and breast development in the newborn. Arch Dis Child 56:770-774

6. McKiernan J 1984 Postnatal breast development of preterm infants. An index of gonadal function. Arch Dis Child 59:1090-1092

7. Andersson AM, Toppari J, Haavisto AM, Petersen JH, Simell T, Simell O, Skakkebaek NE 1998 Longitudinal reproductive hormone profiles in infants: peak of inhibin B levels in infant boys exceeds levels in adult men. J Clin Endocrinol Metab 83:675-681

8. Gässler N, Peuschel T, Pankau R 2000 Pediatric reference values of estradiol, testosterone, lutropin, follitropin and prolactin. Clin Lab 46:553-560

9. Marsal K, Persson PH, Larsen T, Lilja H, Selbing A, Sultan B 1996 Intrauterine growth curves based on ultrasonically estimated foetal weights. Acta Paediatr $85: 843-848$

10. Larsen T 2001 Intrauterine growth restriction - identification, correlation and causation evaluated by use of ultrasound. Dan Med Bull 48:256-274

11. Keitel HG, Chu E 1965 Breast nodule in premature infant. Am J Dis Child 109:121-122

12. Sharpe RM, Walker M, Millar MR, Atanassova N, Morris K, McKinnell C, Saunders PT, Fraser HM 2000 Effect of neonatal gonadotropin-releasing hormone antagonist administration on sertoli cell number and testicular development in the marmoset: comparison with the rat. Biol Reprod 62:1685-1693

13. Main KM, Schmidt IM, Skakkebaek NE 2000 A possible role for reproductive hormones in newborn boys: progressive hypogonadism without the postnatal testosterone peak. J Clin Endocrinol Metab 85:4905-4907

14. McKiernan J, Coyne J, Cahalane S 1988 Histology of breast development in early life. Arch Dis Child 63:136-139

15. Anbazhagan R, Osin PP, Bartkova J, Nathan B, Lane EB, Gusterson BA 1998 The development of epithelial phenotypes in the human fetal and infant breast. J Pathol 184:197-206

16. Keeling JW, Ozer E, King G, Walker F 2000 Oestrogen receptor alpha in female fetal, infant, and child mammary tissue. J Pathol 191:449-451

17. Klein KO, Mericq V, Brown-Dawson JM, Larmore KA, Cabezas P, Cortinez A 1999 Estrogen levels in girls with premature thelarche compared with normal prepubertal girls as determined by an ultrasensitive recombinant cell bioassay. J Pediatr 134:190-192

18. Moore DC, Schlaepfer LV, Paunier L, Sizonenko PC 1984 Hormonal changes during puberty: V. Transient pubertal gynecomastia: abnormal androgen-estrogen ratios. J Clin Endocrinol Metab 58:492-499 
19. Ting AC, Chow LW, Leung YF 2000 Comparison of tamoxifen with danazol in the management of idiopathic gynecomastia. Am Surg 66:38-40

20. Seralini G, Moslemi S 2001 Aromatase inhibitors: past, present and future. Mol Cell Endocrinol 178:117-131

21. Miettinen M, Mustonen M, Poutanen M, Isomaa V, Wickman M, Soderqvist G, Vihko R, Vihko P 1999 17Beta-hydroxysteroid dehydrogenases in normal human mammary epithelial cells and breast tissue. Breast Cancer Res Treat 57:175-182

22. Ekbom A, Hsieh CC, Lipworth L, Adami HQ, Trichopoulos D 1997 Intrauterine environment and breast cancer risk in women: a population-based study. J Nat Cancer Inst 89:71-76

23. Weiss HA, Potischman NA, Brinton LA, Brogan D, Coates RJ, Gammon MD, Malone KE, Schoenberg JB 1997 Prenatal and perinatal risk factors for breast cancer in young women. Epidemiology 8:181-187
24. Hilakivi CL, Cho E, Onojafe I, Liao DJ, Clarke R 2000 Maternal exposure to tamoxifen during pregnancy increases carcinogen-induced mammary tumorigenesis among female rat offspring. Clin Cancer Res 6:305-308

25. Mandybur TI, Ormsby I, Buncher CR 1978 Enhanced development of mammary tumors in rats following transplacental and neonatal exposure to ethylnitrosourea. Cancer Res 38:3182-3185

26. Swerdlow AJ, De Stavola BL, Swanwick MA, Maconochie NE 1997 Risks of breast and testicular cancers in young adult twins in England and Wales: evidence on prenatal and genetic aetiology. Lancet 350:1723-1728

27. Innes KE, Byers TE 1999 Preeclampsia and breast cancer risk. Epidemiology 10:722-732

28. Russo IH, Russo J 2000 Hormonal approach to breast cancer prevention. J Cell Biochem Suppl 34:1-6 